\title{
An Argument for an Ecosystemic Al: Articulating Connections across Prehuman and Posthuman Intelligences
}

\author{
Lucy HG Solomon $^{1}$ (D) Cesar Baio $^{2}$ (D)
}

Received: 8 February 2020 / Accepted: 16 October 2020/Published online: 09 November 2020

(C) Springer Nature Switzerland AG 2020, corrected publication 2020

\begin{abstract}
As an art collective Cesar \& Lois develops projects that examine sociotechnical systems, attempting to challenge anthropocentric technological pathways while linking to intelligences sourced in biological circuitry. As artists we imagine new configurations for what we understand as (social, economic, technological) networks and intelligences. With this ecosystemic approach we consider the possibility of an artificial intelligence (AI) that supports well-being in a broad sense, accommodating relationships across different layers of living worlds and involving local and global communities of all kinds. This thinking is grounded in research by theorists across disciplines, including communications and media theory, microbiology, anthropology, decolonial studies, social ecology, sociology and environmental psychology. At a time when human beings and their ecosystems face grave threats due to climate change and a global pandemic, we are rethinking the basis for our AIs, and for the resulting decisionmaking on behalf of societies and ecosystems. Creative projects by Cesar \& Lois provide alternative conceptual models for thinking across networks, reframing the artists' and potentially viewers' understanding of what motivates and shapes societies. Referencing a series of artworks and the theories that underpin them, this article envisages a sociotechnical framework that takes into account ecosystems and challenges the philosophical orientations that guide society. Degenerative Cultures is an artwork in which the artists overlap microbiological organisms, AI and human systems as a speculative restructuring of networks across human and nonhuman entities. The push for ecosystemic technologies and intelligences is linked to the expansion of community to include planetary constituents, such as nonhuman beings and environments. The artists posit that such ecosystemic networks would be capable of taking into account the planet's human societies as well as nonhuman species and their environments, broadening the concept of community well-being and shifting the technological
\end{abstract}

Lucy HG Solomon and Cesar Baio are affiliated with Cesar \& Lois, art collective, CA, United States and SP, Brazil, cesarandlois.org.

Lucy HG Solomon

cesarandloiscollective@gmail.com

Extended author information available on the last page of the article 
architecture to meet the complex needs of the planet and its constituent parts. The experimental series, [ECO]nomic Revolution, layers Physarum polycephalum, or slime mold, over the mapped demographics of human cities. The species polycephalum references multi-brains, and implies a decentralized logic, which for the nonneurological microbiological network translates to the sharing of nutrients and regulated growth across a culture. Assuming a perspective based in the arts, this proposition imagines a shift from the dominant conceptions of $\mathrm{AI}$ as an individual intelligence and frames it as part of a network that necessarily includes ecosystems. We envision the creation of sociotechnical systems that could be modeled on networked lifeforms that have optimized themselves across millions of years, like the organism Physarum polycephalum, which occurs globally in moist environments, or like those microbial populations within and outside of human bodies, whose percussive biological processing interacts with and alters many layers of lifeforms. We argue that an environmentally responsive intelligence based on relationships across living systems potentially serves a broad community composed of diverse human populations, nonhuman beings and ecosystems.

Keywords Artificial intelligence $\cdot$ Community well-being $\cdot$ Microbiology $\cdot$ Art · Anthropocene

\section{Introduction}

At this crucial point in human history, noted for the Anthropocene, ${ }^{1}$ the crisis of climate change and, more recently, a global pandemic originating from a rapidly replicating microbiological organism, the present tense of humanity shadows the future. The local and global efforts to fight the pandemic have shown to the authors the importance of networks and technology, which, as a communication interface, have become essential to the functioning of human communities. As we humans fathom survival in a very real sense, we must also recognize the existential crises for so many species (Hannah 2012; IPBES 2019), caused and exacerbated by humans and our global industries, including advancing technologies' disruptive extractivism of Earth's minerals (Ribeiro et al. 2015). At this same moment, we acknowledge the importance of the balance of biomes and microbiomes both within and outside our bodies, and the biological linkages which connect species and create nested relationships among whole sets of species: ecosystemic connections. These connections, if replicated within technological systems, constitute an ecosystemic intelligence, an AI that engages with a broad planetary community and which operates according to broad principles of community well-being. We heed Strang's (2017) call to action (also a call for interaction) when she advocates for "a radical re-conceptualisation of human-non-human relationships and the notion of 'community' itself' (p. 272). We redefine community to encompass the living and nonliving layers of the entire planet.

This expansion of our sense of community beyond human connections challenges the dualism that supports human exceptionalism. That dualism has been supported by theories of mind that relegate intelligence to Homo sapiens, and yet our understanding of intelligence

\footnotetext{
${ }^{1}$ Anthropocene refers to "the present, in many ways human-dominated, geological epoch, supplementing the Holocene - the warm period of the past 10-12 millennia" (Crutzen 2002, p. 23).
} 
is changing. Throughout modern society's history, questions such as "what is intelligence?", "what is consciousness?" and "what is sentience?" have been exhaustively discussed. Yet even after hundreds of years neither science nor philosophy are close to a definitive answer (Shaviro 2016). More than a theoretical inquiry, we posit that these questions have been used to justify human exceptionality and ultimately underpin the capitalist, colonial and imperialist project that positions human power over the living world. While it is still possible to find arguments in favor of the idea that human beings are driven by rationality and other animals are driven by instinct (Pinker 2010), cultural intelligence approaches (Tomasello 2014) apply evolutionary theories to explain that general intelligence can be found in nonhuman animals as well (Burkart et al. 2017). As argued by Barrett et al. (2007), the social brain hypothesis is based on the idea that large-brain animals are more likely to achieve cognitive strategies for real-time responses to social life challenges. Those ideas rely on an assumption that "reflects our own unspoken, and often unrecognized, anthropocentric commitments" (p. 561). These studies show that a non human-biased definition and measure of intelligence is needed (Herzing 2014). Examples of such nonhuman intelligence exist in research on swarm intelligence in bird flocks, colony behavior, and bacterial communities, with "collective action arising spontaneously from the sensing, computation, actuation, and communication actions of autonomous agents" (Flikkema and Leid 2005, p. 1). Ancestral knowledge expressed by traditional Amerindian thinkers tenders rich ways of establishing relations between human and nonhuman intelligences (Kohn 2007; Kopenawa and Albert 2013). In this article we discuss some of the ideas surrounding intelligences and their epistemological frameworks while envisioning a nonhuman intelligence that could emerge from the crossing of networks between different lifeforms. In considering this merging of intelligences, we posit the integration of prehuman decision-making (inherent in the growth of microbiological organisms) with posthuman (technological) decision-making. In an art context, Cesar \& Lois introduces a "digital fungus" in the art installation, Degenerative Cultures, which combines prehuman and posthuman intelligences. This installation layers microbiological growth over human texts, output on Twitter as gradually disappearing words, with an AI that learns from microbiological growth patterns and asserts a microbio-logic. In the series of artworks entitled [ECO]nomic Revolution, in which living organisms are placed atop maps of distinctly disparate cities, microbiological organisms distribute resources (in this case, food) according to the microbiological culture's own networked logic.

As an art collective, Cesar \& Lois aspires to merge material experiments with utopian visions for an ecosystemic community. This vision runs contrary to centuries of thinking: Strang (2017) writes, "Nature-Culture dualism has been so normalized over time that it has become seemingly fundamental in everyday discourses and in many areas of 'natural' science" (p. 268) Countering this dualism is complex: "Even ecocentrism maintains the 'human' versus 'nature' duality; it is a mere reversal. Moreover, by framing the environment as 'nature', these modern ways of seeing close off other possibilities to relate to nature, such as those suggested by Heidegger and by Ingold"' (Coeckelbergh 2017, p. 112). Our proposal is not a corrective for dualistic thinking that imperialist countries and their emissaries spread (along with viruses and pandemics). Rather, we envision an intelligence that goes beyond anthropocentrism to ascend to an ecosystemic dimension. This mode of thinking across entities of different natures is not entirely novel, since many Indigenous cultures have long had non-dualistic relationships to their environments, including in the Amerindian concept of multinaturalism (Viveiros de Castro 2014). Gómez-Barris (2017) describes Indigenous societies and spaces that remain outside of modern paradigms: 
Intangible geographies function as entropic spaces that cannot be contained by the extractive view, Western science, the commodity logic of late capitalism, or racial governmentality, but instead are managed by Indigenous peoples, cooperatives, and 'no contact' populations to amplify the multiplicity of the forest's life forms. (p. 20).

Multinatural ways of relating to nature are documented by numerous anthropologists as well as by Indigenous thinkers. In discussing societies whose social orders exist outside of modernity's anthropocentrism, anthropologist Eduardo Kohn (2007) describes the "Amazonian multinaturalist framework" as "one in which culture - and, by extension, the human-ceases to be the most salient marker of difference" (p. 18). Social anthropologist Signe Howell (1996) explains that the Chewong of Peninsular Malaysia:

do not set humans uniquely apart from other beings which they regard as sentient, be they spirits, animals, plants, or things. Second, separation between mind and body, thinking and feeling, are not meaningful to them. Third, within their own environment of the forest they do not oppose a natural world with a cultural world. (p. 128)

Intelligence beyond the human self is explained by Yanomami shaman Davi Kopenawa, whose expansive thinking includes nonhuman systems and other entities: "It is with the xapiri's ${ }^{2}$ songs that my thought can extend to the rivers' sources or towards other distant forests or beyond to the sky's feet" (Kopenawa and Albert 2013, p. 220). In conceptualizing an ecosystemic AI, we aspire to learn from such broad and connected, more-than-human intelligences.

In her writing and talks, Haraway (2016) references ethnographer Strathern's teaching: "It matters what ideas we use to think other ideas" (p. 34). For AIs, it likewise matters what logical pathways an AI uses for its decision-making. MacLeod and Capanni (2010) describe how the network of interactions that exist within singlecelled Protoctists represent an intelligence, evident in the single-cellular organisms' sourcing of food, motility and interactions with other living beings and with their environment. They propose an artificial biochemical network (ABN) and suggest that such a network has advantages over an artificial network modeled on a neural network, namely in that the ABN is connectionist (pp. 123-6). Our concept for an ecosystemic $\mathrm{AI}$ is a networked intelligence, involving an AI that learns from microbiological intelligences which are connected to and interact with their environment. A network based on simple intra-cellular interactions is an important first step towards an ecosystemic intelligence, by which interacting intelligences not only replicate internal cellular processing but also interact across and with others, in the way that humans have recently aspired to think with living others and across species.

By advocating for ecosystemic artificial intelligences (EAI), we align ourselves with the movement to decolonize knowledge, a movement that can also inform and reshape society and technology, such as those social structures and embedded technologies that for the most part still adhere to the archaic principles of a dying world. In response to this movement and its underlying broadening perspectives, we ask: how do we move

\footnotetext{
${ }^{2}$ Xapiri refers to "images of the mythological animal ancestors" (Malaurie, J., p. vii, foreword to Kopenawa and Albert 2015).
} 
forward and away from centuries of progressive thinking, in anticipation of AIs that embrace new possibilities for connected thought?

Viveiros de Castro (Kopenawa and Albert 2015) articulates Kopenawa's philosophy of a "counter-anthropology" which anticipates:

...an imminent destruction of the world, carried out by the civilization that is judged to be the delight of mankind - those people who, freed from all 'retrograde superstition' and from all 'primitive animism', only swear by the most holy trinity of the State, the Market and Science, respectively the Father; the Son and the Holy Spirit of modernist theology. (p. 24) ${ }^{3}$

Following the thinking of the aforementioned scholars, we work from the premise that globalized technological and sociopolitical structures remain rooted in progressive models based in modern paradigms, with exceptions to those models existing within multinaturalist societies. The modernist ideals (of those progressivist societal organizations) never anticipated the complexity of our current times. Tsing (2015) describes those paradigms as "progress," explaining that despite the common association of progress with the nineteenth Century, the "categories and assumptions of improvement are with us everywhere" (p. 20). Given the pre-industrialization origins of these embedded societal structures, it should not come as a surprise that these models appear incapable of dealing with the complexity of our current times. With a monumental shift in planetary demographics, the inadequacies of our current systems to support the diversity and breadth of populations become more evident, as in just the last two hundred years the human global population jumped from one billion in 1820 to nearly eight billion in 2020 (Chamie 2020). Accumulating evidence shows that inherited organizational systems are not designed to support such exponential growth (National Research Council 2014), and we conclude that the organization of societies, now that human populations have multiplied by eight, requires other social structures. Environmental policy thinker Joyeeta Gupta remarks on the inadequacy of existing societal structures for dealing with contemporary environmental circumstances:

We no longer live in a world where great power understandings of geopolitics make sense. The New Earth is marked by a set of emerging ecospace realities that challenge us to reconsider and remake our geopolitical arrangements and define a new social contract. (2016, p. 272)

Our conversations with scholars across disciplines, including sociologists, philosophers, world systems theorists, as well as technologists and artists, move us to ask: where should we look in order to source models for other forms of organization? We argue that we should look to where we always have: the living world.

It can be argued that the current scenario leads to a transformation of the discourse on environmental crises that emerged in the 1970s (Moore 2015). It can also be said

\footnotetext{
${ }^{3}$ From the original: “...A queda do céu entrelaça esses dois fios expositivos para chegar à conclusão de uma iminência da destruição do mundo, levada a cabo pela civilização que se julga a delícia do gênero humanoessa gente que, liberta de toda 'superstição retrógrada' e de todo 'animismo primitivo', só jura pela santíssima trindade do Estado, do Mercado e da Ciência, respectivamente o Pai; o Filho e o Espírito Santo da teologja modernista..." (translated by the authors).
} 
that this scenario demands the creation of concepts, images and symbols that could respond to a different way of conceiving the world, with a more balanced existence of human and nonhuman beings. As artists we feel called to examine this context and produce artworks that could trigger new ways of thinking, intentionally shifting certainties about what it means to be human in order to envision new modes of existence. Assuming the perspective of the artist is a strategy for removing the constraints of the hard and unimaginative side of data, technology and methodology when picturing reality; instead, this creative stance provides a means for speculating about futures that are out of the range of the scientific searchlight. In this article, we examine nonhuman networked decision-making processes through an exploration of the creative research of Cesar \& Lois, a collective composed of California-based artist Lucy HG Solomon and Brazilian artist Cesar Baio. In response to the contemporary context described above, we merge microorganisms and AI in artworks, in order to envision an ecosystemic intelligence that points to a utopic future and is responsive to the complexity of the interactions between biological and nonbiological entities, humans and nonhuman beings. We hold that such an intelligence, responsive to an array of constituents and their contexts, will be capable of making decisions on behalf of a broad community to advance the well-being of the many and the microscopic. Below we detail two artistic series, Degenerative Cultures and [ECO]nomic Revolution, which address this complexity by layering biological and human systems and overlapping their distinct forms of logic.

\section{Case Studies: Microbio-Logic in Bio-Artworks by Cesar \& Lois}

In a series of artworks and creative experiments involving living organisms and current technologies, Cesar \& Lois attempts to merge prehuman intelligences and posthuman intelligences, ${ }^{4}$ in an effort to challenge our human thinking and to reframe the understanding of and role for human logic as only one thread of thinking within the fabric of living beings and their habitats. Degenerative Cultures posits a bhiobrid (biological and digital hybrid) network in which living microorganisms and AI work together: a generative algorithm modeled on Physarum polycephalum (slime mold) mirrors the growth logic inherent within the networking organism.

In the physical artwork, which received the 2018 BCS Lumen Prize in AI, the living organism's growth over the text of a book, visible through a dome, generates a Twitter feed that reveals, through ever-shifting textual output, the organism's growth over the book's words. The book and the text which act as substrate carry meaning: we select texts that are rooted in this Western tradition that isolates human logic apart from and even above the living world, and that draws a line between the two. A grid of oats is placed over the text, and a technological system monitors the culture's growth across the page, effectively redacting the text as it grows. The physical exhibition of microbiological growth logic "consuming" and overtaking the text is connected to a larger critique of humanity's role within the Earth's systems, including the role of human logic within prevailing technological systems.

\footnotetext{
${ }^{4}$ In the following sections these concepts of prehuman and posthuman intelligences are developed further.
} 


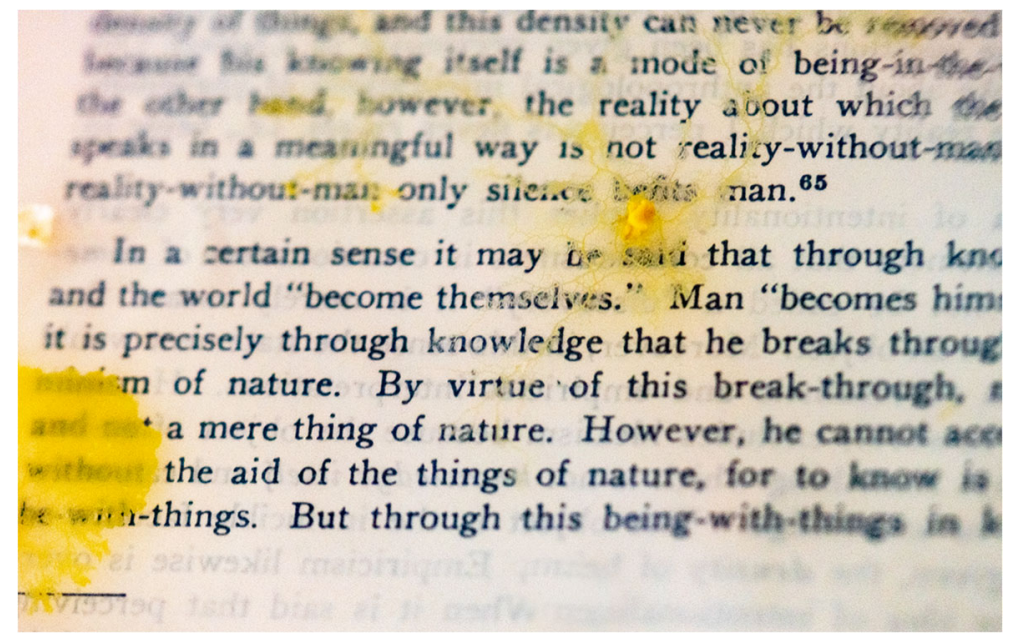

Fig. 1 Physarum polycephalum grows over a book as its substrate, growing over words and "redacting" text as the microorganism progresses; Uncommon Natures, Lumen Prize exhibition in Brighton Digital Festival in Brighton, UK, 2018

In tandem with the living organism, an AI, which we refer to as a digital fungus, searches the Internet for texts that similarly exhibit a predatory approach to living systems. This digital fungus builds a database of texts that advocate human interventions in ecosystems, plots those texts on the screen, and then degrades the text in the way that Physarum polycephalum consumes oats. By positing a cooperative model for deconstructing the logic

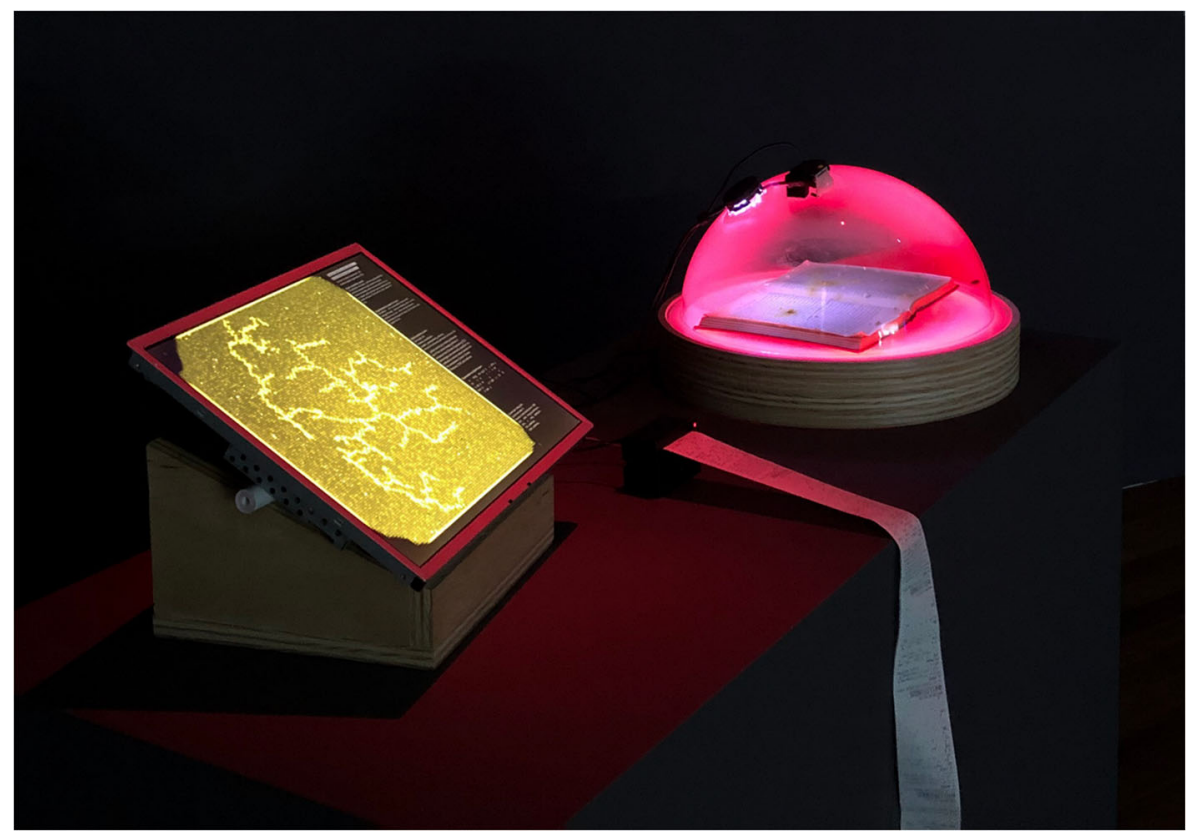

Fig. 2 An AI modeled on Physarum polycephalum searches the Internet and corrupts texts on weather modification; NTU Global Digital Art Prize Exhibition in Singapore, 2019 
of human superiority over living systems, we anticipate an ecotopian AI, in which computerized logical processing is modulated by the ecosystemic growth logic and values embedded in the decision-making processes of living systems. Thinking of what could emerge as an ecosystemic knowledgebase, we ask, what will be the outcome when these two types of intelligences work together, the prehuman (microbiological) and posthuman (computergenerated)? How could this bhiobrid system make decisions that take into account whole ecosystems, moderating between and adjusting on behalf of individual nodes, and on behalf of a planet-sized and nuanced community? Departing from these questions, we speculate about new models for the technological development of AI systems. Instead of basing AI on human neuroscience, we wonder if AI could be reoriented to microbiological systems sourced in nature. This is the premise for an AI designed for community interests, where community implies not only human beings and human social systems but extends to all of earth's systems and to the wide range of entities implied in those systems. Such an AI serves community well-being in the broadest sense, while necessarily being shaped by and supporting the weakest nodes of the network, such as threatened species and their environments as well as vulnerable human groups and human societies.

Because of the organism's modulated, networked growth, Cesar \& Lois looks to Physarum polycephalum to generate new ideas for thinking across networks and integrating with global ecosystems. This is community in a broad (and both local and global) sense, as in Haraway's (2016) multispecies worldings, rich with interconnections. We are wary of making a one-to-one comparison between global ecosystems and microbiological systems such as Physarum polycephalum, and yet we find much to learn from the juxtaposition of these macro and micro networks, including in examples of the microorganism's community coherence, and the organism's balancing of the well-being of both the whole with that of the constituent individuals. ${ }^{5}$ We find that these living systems have much to teach us about how we organize human communities, and especially the social organization within cities. When layering the networked logic of Physarum polycephalum over different cities, we find that a community's wellbeing can be mapped and visually assessed as a living, growing data visualization. In the series, [ECO]nomic Revolution, we are thinking about the possibility of different networks for those human communities, rethinking the organization and well-being of our communities through the filter of microbio-logic.

[ECO]nomic Revolution includes a series of art experiments, using the demographics of cities as substrates for the growth of the living culture. Physarum polycephalum grows according to the wealth and population distribution of the contrasting neighborhoods of Palo Alto and East Palo Alto in California, as well as areas in Durban, South Africa with great wealth disparity and contrasting ethnic populations. In the Los Angeles-based experiment, Physarum polycephalum grows along Venice Blvd., moving from West Los Angeles - where the population is not as dense and per capita income is high - to East Los Angeles, with a consistent high-density population and low incomes. In the map including contrasting neighborhoods spanning Venice Blvd. in Los Angeles, each neighborhood's per capita income is represented by oats (1 oat is equivalent to $\$ 10 \mathrm{~K}$ per capita income); human population is represented by the concentration of culture, with more yellow indicating more densely populated

\footnotetext{
${ }^{5}$ Cesar \& Lois observed this balanced resource distribution in our growth of Physarum polycephalum in the different iterations of [ECO]nomic Revolution.
} 
neighborhoods ( 1 dot starter culture for each $5 \mathrm{~K}$ people per square mile). The networking microorganism, growing over the map according to the city's demographics, with oats representing income, at first mimics how human cities operate. With an abundance of oats, the culture on the West side grows to capacity and then overgrows the area, while the more concentrated culture on the East side, starved of resources (oats), blanches - showing signs of failing. This growth model resembles the gentrification that happens across human cities, as wealthy populations outgrow the area and seek to inhabit adjacent resources and space.

Ironically, the microorganism known for equitable distribution perfectly models human inequity - until, that is, Physarum polycephalum connects up with the other branches that represent the failing concentration of culture. Once the organism connects and forms a network, the system begins to modulate its growth and distribute nutrients in order to sustain and support the other nodes. For Physarum polycephalum, the system's logic overrules the desire to expand. By growing networking microbiological systems over human systems, the illogic of one becomes apparent through the logic of the other. In this case, Physarum polycephalum highlights the illogical distribution of resources and population across human communities, a distribution which lends to greater inequities across cities. The project underlies how microbiological processing of information, apparent in the decision-making that distributes resources across the network, can serve as a launching pad for rethinking human systems.

Our experiments and artworks involving Physarum polycephalum provide a means for rethinking "the 'metabolic interaction' between human beings and nature" (Foster et al. 2010, p. 434). For us as artists, this non-neural microorganism presents questions about what could motivate a non-neural network's decision-making across individual nodes, with unified intention. We ask, how could we apply those same principles of regulation, growth and information processing to technological systems, and how might this benefit a collective across scales, species and ecosystems? This question is meant to galvanize a new way of thinking about relationships across individuals and

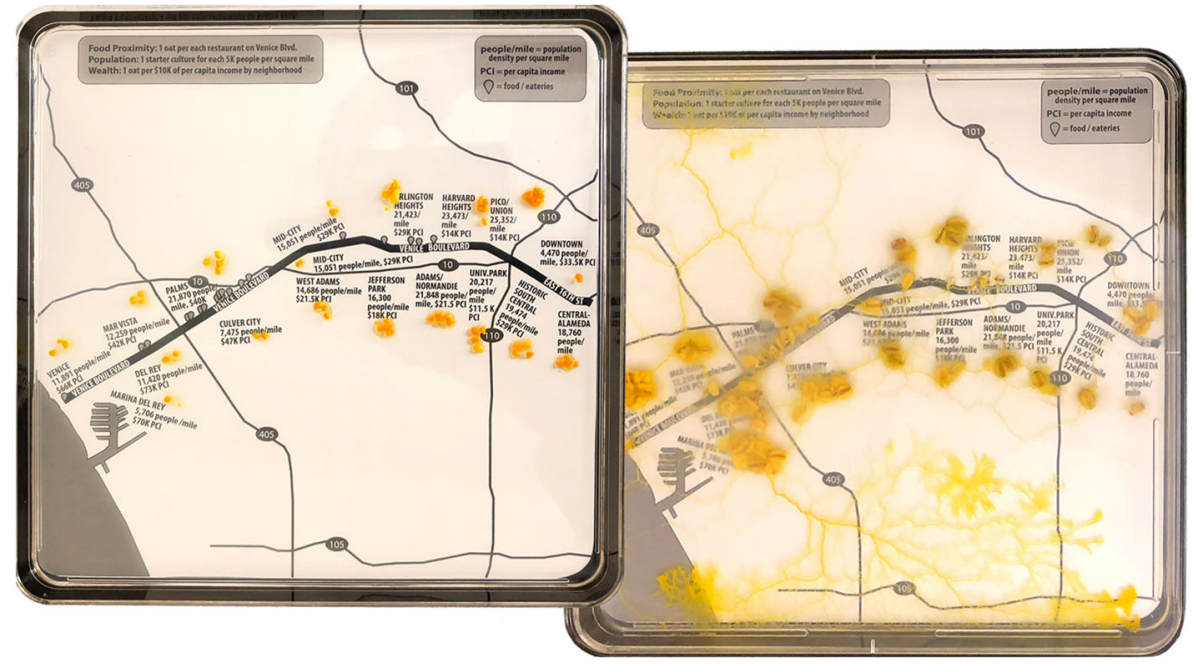

Fig. 3 The before and after images of the growth of Physarum polycephalum along Venice Blvd.; shown in Microgentrification takes over Los Angeles, JAUS, Los Angeles (2018) 
societies, beginning with those that are mitigated by technological transactions; it does not proffer a fix-all strategy. We heed the warning against problem-solving that aspires to invent (and capitalize on) new solutions rather than adjust ways of being:

The dominant approach to the world ecological crisis, focusing on technological fixes and market mechanisms, is thus a kind of denial; one that serves the vested interests of those who have the most to lose from a change in economic arrangements. (Foster et al. 2010, p. 430)

The artworks detailed above do not propose an environmental, economic or technological solution but, rather, are intended as a societal provocation for the development of new metabolic systems that support societies, ecosystems and earth in a broad sense. An ecosystemic logic within sociotechnical systems (with planetary community wellbeing encoded in the EAI's foundational algorithms) could potentially shift the metabolic interactions between human and nonhuman entities, changing the behaviors of individuals and groups.

Pushed forward by our research, these artworks provide a methodological instrument for conceptualizing logical models that intermix human, microbiological and computer-based decision-making and networking. The speculative nature of these works is intended to trigger questions about how resources and power are shared among nodes in networks, how some beings exercise power over other ones, how anthropocentrism disconnected humans from other living beings, and how all of these become embedded as values that are encoded in societal structures. With these provocations in mind, we envision an ecosystemic intelligence as the basis for the development of AI-based systems that could emerge from the crossing of human, prehuman and posthuman ways of thinking. Linking our artistic approach to this vision, our artworks comprise a series of conceptual propositions, whose aspirations and principles we consider foundational for this hypothetical system. The conceptual development of a utopic ecosystemic AI establishes an ecosystemic basis for societal structures that repositions human existence as a part of an intricate ecosystem and a broad planetary community. In the text that follows, we analyze how these artworks respond to the context of a broad community well-being.

\section{Analysis: Networked Living Beings as a Basis for EAI}

When analyzing the creative process and the final artworks introduced above, we consider how each responds to the critical state of relations between humans and the environment. As artists creating speculative artworks that merge AI and the networking of living microbiological organisms, we propose a new conceptual approach for the development of technological systems we call bhiobrid AI. This merging is conceptually linked to our vision for an EAI. We surmise that at a time of climate crisis, when global ecosystems are stressed, weather patterns disrupted, virus infections expanded to a global scale pandemic and whole species displaced or decimated, societal systems, their anthropocentric values and the human thinking that led us to what has been called the Anthropocene come under question. And as we examine those systems and the intelligences that are based in humanness, we find ourselves asking an age-old 
philosophical question in an updated technological and ecological context: what does it mean to be human? This self-examination, for us as artists, becomes an inquiry not into the singular self but into our many selves, inclusive of the microbial inhabitants of our human bodies, and simultaneously a search to understand how we as members of a more-than-human community of beings can advocate, develop and practice ecosystemic thinking. What does community well-being look like when that community is expansive and inclusive of microbial communities as well as vast landscapes? As with Physarum polycephalum's regulated distribution of resources, ecosystemic wellbeing, a broadened concept of community well-being, requires unbiased decisionmaking that favors the equitable distribution of resources, which is admittedly a tall order for human-centered and human-created sociotechnical systems.

As artists, our objective is to rethink human systems and to propose new ones that are ecotopian, ideally engendering planetary and community well-being rather than exploiting nonhumans and their environments as ecological resources. The alternative and currently the normative technologies - those human technological systems which fulfill particular human goals without factoring in external networked living and nonliving entities - ignore the needs of large populations of species, including marginalized human societies and communities and, though less observed within sociological contexts, microbes (which make life on earth possible). Even the creation of those technological systems, dependent upon extraction, is linked to environmental predation and the inequitable distribution of resources and labor, as illustrated by artists Crawford and Joler (2018) in their detailed visualization of an AI system's relationships to and impacts on people and environments. As the chart reveals, the creation and implementation of such humanserving systems harms planetary well-being (Crawford and Joler 2018). At a moment of climate crisis and in order to serve the broader ecological community's well-being, we as artists feel an ethical imperative to align innovation in AI with intelligent systems embedded in ecosystems. In contrast, the majority of articles about ethics and AI are anthropocentric, focusing on maintaining the dignity, wellbeing and authority of humans. For example, in the article, "How AI can be a force for good," the subtitle ("An ethical framework will help to harness the potential of AI while keeping humans in control") and introduction restrict that AI's potential good to humanity: "For the well-being of humanity it is crucial that this power is used as a force of good" (Taddeo and Floridi 2018, p. 751). We question the historical division between humanity and other living entities and the supposed privileged position of humanity over other living beings and elements of the environment. In doing so, we create artworks that imagine how an AI based in nonhuman systems could process multispecies intentionality on behalf of global ecosystems better than the anthropocentric models of artificial neural networks. In our experiments with Physarum polycephalum we have observed what we interpret as prehuman intelligence, an intelligence embodied in the observable logic of microbiological growth and which takes into account crucial environmental factors such as climate conditions and adjacent organisms. While microorganisms compete with and even consume one another, systems of networking microbes provide alternative models for making decisions on behalf of communities, decisions which benefit each node of a network without privileging a single entity or centralized decision-maker. Prehuman thinking can be found in the networking growth and 
regulation of Physarum polycephalum as well as across our cells and selves, when taking into account the exchange of information across microbial populations within the human microbiota.

Based on the inequitable distribution of resources and opportunities across the globe as well as assessments that current sociotechnical structures cannot accommodate the size and diversity of human populations (National Research Council 2014), we seek new ways of thinking across systems so that we may achieve the complex collective intention that diverse global populations (and localized populations within those larger societies) demand. Flusser (1999) argues that the form of our technology underlies and even generates societal values. We consider how an AI based on human neuroscience makes societal decisions in the way that an individual human might, which is not necessarily aimed at achieving equity across humans, or across species and ecosystems. Based on Flusser's argument, we assert that AI modeled in a human way generates an intelligence that reflects the centralized decision-making process of that human intelligence and typically serves human-specific goals. For example, artificial learning aimed at building empathy and assessing emotion may be reflective of human values encoded in language. Such AI could be intended to empathize with humans and to advance certain human goals. Language associations fed to AI could create better computerized medical aids, as well as AI that can process feelings. Cassell (2019) implies that improvements to social well-being refer strictly to human (and computeraided human) interactions: "The underlying mission is to better understand social interaction and to build machines that work more collaboratively and effectively with humans" (p. 29). Cassell elaborates on how natural language understanding can build more socially aware AI and has the potential to foster stronger social interactions in children. We suggest that while studies on the impact of AI on human relationships are valuable, there are broader implications of human-centered digitized decision-making. Such implications, for example, extend to considerations of the ecological outcomes of the base human logic on which the AI trains. We ask, what if an AI could consider the composite needs of nonhuman lifeforms and include their interests in decisions?

Our collective Cesar \& Lois proposes a conceptual framework for a new direction for AI, one that does not privilege select human beings or human beings in general and looks instead to intelligences that predate human thinking - to prehuman intelligences. AI is often framed as posthuman, expanding the capacity of our human selves and reformulating even the definition of what it is to be human. Cesar \& Lois proposes that prehuman and posthuman intelligences, working in collaboration with one another, make possible thinking on a scale that is more-than-human-with an intelligence that is ecosystemic. We posit that an integrated AI, an EAI that merges prehuman and posthuman thinking would best meet the challenge of producing equitable decisionmaking, without elevating human beings over our microbes, other species or their habitats. This approach to an AI for broad planet-scaled community well-being expands the definition of community to a complex network of entangled globally and locally scaled ecosystems and their inhabitants. Tsing (2015) and Haraway (2008) articulate entangled beings as interdependent species, positioning humans as interconnected with other beings ("kin") (Haraway 2008, p. 134), and arguing against the human exceptionalism inherent in forward-facing human aspirations of "democracy, growth, science, hope" (Tsing 2015, p. 21). Haraway (2008) further contextualizes human exceptionalism within what is often categorized as Western thinking: 
In the lineage of Western philosophers with and against whom Derrida struggled all his life, only the Human can respond; animals react. The Animal is forever positioned on the other side of an unbridgeable gap, a gap that reassures the Human of his excellence by the very ontological impoverishment of a lifeworld that cannot be its own end or know its own condition. Following Lévinas on the subjectivity of the hostage, Derrida remembers that in this gap lies the logic of sacrifice, within which there is no responsibility toward the living world other than the human. (pp. 77-78)

In seeking thinking that accommodates interdependency over separateness, we look to those microbiological beings that exist as entangled networks. Prehuman thinking rests in a logic that is microbial in origin - an embodied thinking that acts as a model for ecosystemic processing of information and resources. Prehuman intelligence, when considered in tandem with human thinking, likewise challenges what we think of when we consider what it means to be human. The analysis of Cesar \& Lois' artworks propels the discussion in the next section, in which we address how prehuman logic can inform human technological systems.

\section{Discussion: Pre and Post-Anthropocentric Thinking}

In our discussion of prehuman intelligence, we refer to how living organisms, many of them without any nervous system, are able to collect information about their environments, process such information, adapt to internal and external conditions, solve problems they encounter and achieve goals. This kind of intelligence is established by their need for survival. In some cases, organisms organize themselves in complex networks and are structured based on models that are so efficient that they can compete with the logic inherent in human systems of networking and production. Examples of these complex behaviors in forming networks of living organisms abound. Studies published since the 2000s show the complexity of organization and decision-making by organisms such as Dictyostelium discoideum (Johnson 2003). This organism is a eukaryote that is capable of transitioning from a set of single-celled amoebae to a multicellular slug, and then into a fruiting body within its lifetime. For Johnson (2003), the experiments carried out with Dictyostelium discoideum demonstrate a classic study on non-centralized decision-making processes that emerge in complex systems from a bottom-up structure. Like Dictyostelium discoideum, Physarum polycephalum does not have a brain, nervous system or neural cells; however, it demonstrates optimal decision-making across a system and is sometimes referred to as an intelligent organism. Among the most striking behaviors in Physarum polycephalum is its ability to solve mazes (Nakagaki 2001), as well as its way of connecting food sources through an intricate network of growth tunnels in an optimized way. Within the context of art projects developed by Cesar \& Lois, non-neural microbiological logic, which is termed microbio-logic and defined as logic inherent in microbiological systems that mitigate individualized need in order to advance a community, works together with a computational system to question the human legacy of seeking control over the living world and, parallel to this, the accelerating demolition of non-human living systems and their environments. 
The root of the species name of Physarum polycephalum refers to many heads, or brains. This microorganism possesses a kind of intelligence by which it shares information across its many nodes (nuclei), growing as a form of life that is both individual and collective, moving efficiently towards and even remembering the location of food. To perform these tasks, Physarum processes information and establishes memory by leaving a trace of plasma wherever it goes. This allows the organism to be able to recognize the chemical information of past experiences when faced with a path already taken. With this, the organism avoids wasting energy in the search for food and does not starve the distant nodes of networking nuclei. The trace left by the organism acts as a source of information, which is accessed at the moment when other nodes decide to move through the same area. Because of these characteristics, Physarum polycephalum is a natural choice for creative experimentation. This organism, in a sense, is an intelligent participant in some of the projects Cesar \& Lois has developed in order to consider the composition of a bhiobrid network - one which integrates Physarum polycephalum's networking with the Internet, a human-centered technological network. This integration, which manifests as the processing of texts and microbiological tweets, is a provocation for those who examine and propose new AIs to envision ecosystemic intelligences.

Shaviro (2010) analyzes the cognitive ability of Physarum polycephalum from the theory of the extended mind, which argues that the mind can be extended by external devices and push cognition beyond the capabilities of the brain and the body. Stiegler (1998) and Combes (2012) find that in general, this theory refers to the capacity for enhancing human intelligence with appended technologies, such as the ability to store and process information in digital systems. Physarum polycephalum uses a series of pathways as a way of sensing its environment, collecting information such as humidity, potential of hydrogen $(\mathrm{pH})$, temperature and light, with the organism organizing itself internally, changing its metabolism and its pulsation state, which sends chemical signals and nutrients to all parts of the networked cell (Mayne and Adamatzky 2015, p. 2). Shaviro argues that Physarum polycephalum does not operate in accordance with what human social science scholars have understood as rational choice. For Shaviro (2010), "Slime molds represent an extreme ontological case, in which the contrast between internal and external definition, as well as between individual and collective determination, is pushed to its most intensely ambiguous point" (online). Thus, Shaviro (2016) considers the sentience of this microorganism as a form of awareness grounded in experience in the world and evident in a nonhuman decision-making process that "continually prods, pokes, and provokes its environment" (p. 214).

According to Jones (2015), a researcher in unconventional computing, the organism's complex behavior in decision-making is related to Physarum polycephalum's ability to respond to the environment - that is, adapt to external conditions:

The organism behaves as a distributed computing material, capable of responding to a wide range of spatially represented stimuli, including chemoattractants, chemorepellents, temperature changes and light irradiation. Slime mould performs these complex feats using only very simple components and its behaviour has even been described as intelligent. How can such complex behaviour emerge in such a simple organism? (p. 1). 
This complex interaction with the environment means that this microorganism has the capacity to distribute resources along its intricate network of nuclei in an equitable manner. Any food source found along any branch of growth is digested and distributed across the network. Decisions such as whether the organism will enter a state of hibernation, expansion, retraction, reproduction, where to grow, how many expansion paths will be opened, among others, are made based on the bottom-up system described by Johnson (2003), according to a logic that does not support a centralized data processing system.

Beginning with a distant perspective, taking into account the history of evolution, prehuman intelligence, which is even evident in very simple systems involving single-celled organisms, is, in our view, ubiquitous. These organisms and their ways of functioning are the result of billions of years of evolution, and they remain viable today and integral to ecosystems. Their ability to respond to the environment has been tested in ways that we cannot precisely quantify. The current forms of microbiological systems, and the functioning of individuals as complex networks, are the result of this adaptation across billions of generations. This, in accordance with Shaviro's (2016) study, means that there is a memory within bodies, that such systems materialize knowledge about themselves and the environment. As evidenced in this discussion, Microbio-logical ways of responding depend on the ability to understand the environment, process this information and respond to it with concrete interventions in the surrounding reality. Thinking about these systems in this way, these organisms process information in a way that is not so dissimilar to computer systems.

When the pioneers of computer systems began to discuss the possibility of AI, they sought to create machines that were capable of performing functions that, if performed by humans, would be considered intelligent: "An attempt will be made to find how to make machines use language, form abstractions and concepts, solve kinds of problems now reserved for humans, and improve themselves" (McCarthy et al. 1955, p. 13). Early models of and projections for AI were based on human intelligence. Minsky (1968) noted that both $\mathrm{AI}$ and simulation of human thought were "using human problem-solving behavior as their most important model ... We expect substantial divergences to appear in the future, e.g., because of the power of certain logical and mathematical formalisms too alien to normal human thinking" (p. 8). Two aspects stand out for us in these descriptions: first, the reference of the human being as a central model of intelligence, and second, the aspiration for machines capable of solving problems based on rational computing processes (acquisition, analysis and output of information).

Currently, AI systems have gained prominence and are present in many forms of technological enhancements from search engines on the Internet to self-guided car prototypes. Such systems are able to identify objects in a photograph, understand and simulate human language, and find the shortest route for a car's travel. What these systems and features have in common is their ability to learn to identify and process patterns. These patterns can become a blueprint for digital and social interactions, and yet there is no evidence that these systems are capable of predicting the percussive societal impacts of those digital processes. We observe that the market is the key driver of technological development, rather than societal outcomes. Present-day technological systems advantage efficiency (Anthes 2013). Efficiency lends profitability. Not surprisingly, the beneficiaries of new technologies are also the beneficiaries of capitalism (LaFrance 2016). 
Miller (2011) introduces rules for the ethical development of computing artifacts while emphasizing the moral responsibility of the developer in gauging the potential impacts of sociotechnical systems and their components. Discussions and case studies within academia on critical making, or practice-based research, situate the development of new technologies and tools within their societal contexts (Ratto and Hertz 2019; Harwood 2019). Ratto describes the process of embedding critical making experiences into curriculum: "I give students the specific prompt: 'Build a moral technology"” (Ratto and Hertz 2019, p. 24). Harwood (2019) documents the Critical Technical Practice of the former Centre for Cultural Studies at Goldsmiths, University of London, where questions around technical development were considered alongside questions concerning the ethics of those technologies, as a "way to examine the live techno-social aspects of contemporary digital culture" (pp. 3132). Artists who are engaging in this discourse on critical making are also shifting the conversation for developers (many artists who identify as critical makers are also developers). In describing the link between machine learning and ethics as an incentive for developing Feminist Data Set, Sinders (2019), an artist and machine learning and machine design researcher, cites both the critical engineering manifesto as well as the Feminist Principles of the Internet (p. 87). Having developed an AI intended to disrupt biases inherent in technologies, Sinders (2019) considers the sociotechnical impacts of computer artifacts, as Miller (2011) lays out in The Rules. Similarly, in interrogating AIs that disenfranchise Black healthcare patients, Benjamin (2019) uncovers the sociotechnical impacts of racial bias in algorithms. It is apparent that technologies that are designed by and for human beings, such as health care tools, can benefit certain humans and disenfranchise others. Expanding beyond human populations, if a technology's architecture is designed by and for human beings, which entities are disenfranchised?

As visionaries for a biologically-integrated EAI, meaning an AI that does not privilege humans in the system, we also look to studies that advocate measured innovation in consideration of societal outcomes (Mamo and Fishman 2013). This balance (the advance of tools coupled with an analysis of projected repercussions) is evident among the explorations of both the ethics and efficacy of experimental technologies. Some technologists and theorists have been examining how to instill ethical paradigms into the development of new technologies. At the same time, sociologists recognize that we exist within a "new technological paradigm" (Castells 2000 , p. 694). Bratton (2015) envisions a new political geography redesigned to consider "this era of planetary-scale computation" (p. 3), which entails "...[a] multilayered structure of software, hardware, and network 'stacks' that arrange different technologies vertically within a modular, interdependent order” (p. 4). This reenvisioning of the logical processing of complex human systems is based on the "threads from different intellectual fabrics" which are then knitted together (p. 4). We find that this movement in thinking is a technological response to a collapse in both ecological and human systems. Considering the thinking of Flusser (1999), who roots societal systems to the architecture of our technologies, we ponder how ecological systems also intersect with our human societies and technologies. Given the inherent connections across social, technological and ecological systems, in our view it is important that AI development expands inquiry into the inherent and even ingrained values of technologies (Miller 2011) to include biospheric values, with attention to the 
well-being of broad community (human-nonhuman-ecosystems-planet) and of that broad community's diverse constituents.

In anticipation of the adoption of prehuman logic models, we speculate on the creation of AIs that originate in other forms of intelligence manifest in that microbiologic. Such an EAI would necessarily be multispecies, communal and networked rather than individualistic. We claim that an attitude towards the self as selves is both preanthropocentric, in that this selves-conceptualization predates modernity's focus on the individual (within centuries-old cooperative models of society), and post-anthropocentric, coming, as it does, after a heightened period of anthropocentrism, culminating in global capitalism. We maintain that a post-anthropocentric AI could potentially think with human beings, across societies, and for whole ecosystems. This intelligence could emerge from the combination of post-anthropocentric and pre-anthropocentric thinking, as both terms here refer to ecosystemic thinking that runs counter to human exceptionalism. Our proposal for this model of thinking is a departure from the focus on the individual resulting from modernity, which inarguably has peaked during global capitalism, and moves towards the ecosystemic thinking of cooperative and Indigenous groups and multinaturalist thinking that predates modernity and prevails today. We believe that such an AI would be capable of thinking with an expansive community, inclusive of human groups as well as ecosystems and their entangled inhabitants.

We hold that this expanded capacity for thinking has implications for the morality of decision-making, and for community well-being on a broad scale. Research in environmental psychology outlines different categories of moral responsibility to explain why individuals are motivated to behave in ways that benefit the planet, its living systems and inhabitants. These include anthropocentric values, which foster social responsibility to one another or on behalf of future generations, and biospheric values, which motivate individuals "to protect the environment because of the consequences for plants, animals and the biosphere" (Nolan and Schultz 2015 p. 628). This leads us to imagine AIs based on biospheric values, such as those implied in Kopenawa's (Kopenawa and Albert 2013) articulations of ecosystemic thinking. We imagine EAIs that think not as individuals but across and with layered ecosystems.

While specific values shape human thinking and behavior with regard to the environment, sociotechnical systems help to shape and reinforce those values. In an industrialized, increasingly communications-based society, Flusser (1999) pronounces: "The question of the morality of things, of the moral and political responsibility of the designer, has, however, taken on a new significance (indeed an urgency) in the contemporary situation" (p. 66). As argued above, technologies that facilitate and shape communication networks, global economics and supply chains, and machines' processing of information also inform human societal values. We propose a radical rethinking of form, resisting the human narcissism that reimagines the world for human interests and builds our technologies according to the needs of select groups of humans (in isolation from other species and ecosystems). Kohn (2013) seeks to better understand the patterns that emerge from the form of the forest, a pattern that he relays as thinking: "Rethinking cause through form forces us to rethink agency as well" (p. 21). Kohn connects patterns of thinking (in a forest) to the type of thinking that becomes possible. That expanded thinking amplifies phenomena and may just "help us understand how we might better live in a world we share with other kinds of lives" (p. 22). Thinking beyond-the-human is essential to an "ecological ethics," which, as environmental philosopher Mick Smith (2011) writes in his analysis of Derrida's philosophy of ethics, raises 
"questions concerning the singular significance of beings other than animals, too: trees, fungi, river, rocks" (p. xix).

This concept of thinking beyond-the-human nests naturally with theories of anthropologists Viveiros de Castro (2014) and Tsing (2015), whose ideas synchronize with the words of Kopenawa (Kopenawa and Albert 2013) and the writings of plant ecologist Kimmerer (2013), who record Amerindian people's connected and nonlinear relationships with the living world. When Kimmerer (2013) encounters a lost term for emergence in the writings of Anishinaabe ethnobotanist Keewaydinoquay, what she uncovers is more than a word: puhpowee is "the force which causes mushrooms to push up from the earth overnight"” (p. 49). In considering that nonhuman sensation of puhpowee, we observe that contemplating connections across and through microbiological organisms offers potential new forms for thinking. As with the richness in these ecosystemic relationships and the language that describes those, our proposal for a microbio-logical AI anticipates an intelligence whose form is ecosystemic and whose underlying processes support different nodes in a complex network, and the overall well-being of a broad ecological and connected community of human and nonhuman entities. Our proposal, which inserts microbiological intelligence into human systems, has parallels in studies in the social sciences that seek to advance understanding of humans and societies through the lens of the biological sciences. In the next section, we contemplate those studies and consider their provocations for conceiving of intelligence in new ways while recognizing the pitfalls that can arise from mirrored approaches.

\section{Provocations and Limitations: The More-Than-Human Challenge of Networked Thinking}

For psychology and neuroscience researcher Tomasello (2014), the development of human thinking stems from a shift in perspective among great apes in response to the challenges of their surroundings. His shared intentionality hypothesis states that new forms of thinking were engendered by collaborative and communicative interaction in order to, for instance, cooperate to acquire enough food for survival. Tomasello (2014) analyzes three different attitudes related to thinking and, overall, the establishment of individual, joint and collective intentionality - collective intentionality as the most advanced way of thinking and which enabled humans to build our current societies. While Tomasello (2014) validates the importance of establishing collective intention in human evolution, we observe that the development of collective goals that he traces is limited to groups that are delineated by specific boundaries, which ultimately fosters individualistic goals, as with delineated groups of great apes. This lack of genuine group intentionality across societies (where there is cohesion among groups) interferes with the ability of societies to cooperate effectively in a time that requires global synchronized efforts in response to pandemic viral threats and climate crises. ${ }^{6}$

From the vantage of ecologically-focused artists, and considering the role of humanity within a complex global environment, we argue that human societies remain individualistic

\footnotetext{
${ }^{6}$ See evidence of lack of group intentionality in the myopic actions of individual nations, exemplified by U.S. President Donald Trump's pullout from the Paris Climate Agreement (Tollefson 2017).
} 
and isolated by political, economic and cultural barriers. This isolation is in opposition to the ideals of a broad community well-being. We hold that it is important to the reshaping of our sociotechnical systems (and our thinking) that we build into our technologies the complexity of interrelationships that exists across living beings and environments, social groupings and societies. This reshaping of technology asserts that human beings are part of an intricate network of living and nonliving systems, which world systems theorist Moore (2015) calls the web of life. Our conception of a new status as networked selves demands a new way of relating, not only to one another but to other beings and environments; that way of relating depends on new ways of thinking.

Emergent ecological and societal concerns arise at a time when the global human population is networked through technological systems and when technologists are rapidly expanding the capacities of AI. Human impact is changing the global environment in a radical way (Harden et al. 2014, p. 6). The hypothesis of human mass extinction as a potential consequence of climate change aligns with the insertion of the Anthropocene. In this epoch, the planet is incapable of consistently supporting ongoing life for many species, including humans (IPBES 2019). We argue that ecosystemic thinking is essential for the well-being of the many layers of the broad global and local communities, including for ecosystems and their inhabitants, for human societies and for human health. Our logical conclusion is that the global pandemic and spread of COVID-19 reinforce this argument and enunciate the challenges that face an outsized human population. Adopting an ecosystemic perspective, we hold that planetary community well-being entails that human cohabitation with other species ideally reflects human interdependence with those living others, ranging from animals to microbes, and requires a rerouting of our thinking that takes into account those connections. We propose that our technological systems require a similar rerouting.

The ensuing question is: will we be able to figure a way of thinking (and acting) together in response to global and local challenges to this broad ecological and societal (global) community well-being? We believe that thinking together about humanity's role in ecosystems necessarily involves living and nonliving constituencies in the architecture of an ecosystemic form for decision-making. Building on Tomasello's (2014) theory of shared intentionality, it seems that one viable response as a collective is to think and act with an awareness of local and global repercussions. In our experimental thinking, that collective expands to include the broad community of human and nonhuman interactors. The repercussions for systemic decisions within that broad community are ecological, and they are also social, political, and economic.

In the past few decades, a number of studies demonstrate different instances of complex behavior in massive populations of nonhuman systems, including in bees (Johnson and Jasper 2016), ant colonies (Gordon et al. 2017), fungi (Fricker et al. 2007; Fricker et al. 2017) and bacteria (Ben-Jacob 2008). In certain strains of bacteria, massive bodies of individuals can grow to the order of billions in a few hours (Gibson et al. 2018). At a time when human networks appear ineffective in organizing themselves en masse, as artists we ponder what humans can learn about networked decision-making and problem-solving from complex living systems. As we discover how networked lifeforms make their decisions and manifest their sentience, we are more and more convinced that we must learn to think together in a fuller sense, and to conceive of a networked cross-species consciousness.

As artists we speculate that, perhaps, in order to respond to the challenges that overwhelm human individuals and societies, what we humans should do now is 
examine the prehuman thinking that originates in cooperative living systems and to articulate the models that drive these systems in order to create ecosystemic AI (EAI). Such cooperation can be found among organisms that coevolved over billions of years and survived through coordinated composite thinking. The complex and layered relationships between organisms can extend to their ecosystems, as with the symbionts, hot cave bats and their resident parasitic flies, whose tropical cave climates they cultivate and which also cultivate them (Morse et al. 2012). Considering the relationships between sociotechnical apparatuses and the values and knowledges embedded in them, as Flusser (1999) pointed out, we envision that this EAI would materialize a new step in the evolution of human and nonhuman collective intentionality, one that crosses scales from individuals to whole groups (numbering in billions), towards a networked multispecies thinking. In developing an imaginary scenario for networked thinking involving human and nonhuman as well as living and nonliving entities in our artworks, we probe how living microbiological cultures can inform technological systems and challenge our human ways of thinking.

The hybrid biological and AIs presented above are not a means for achieving ecotopian ideals but for presenting ideas, the seeds for those ideals. By examining what AI for community well-being entails, and by expanding community within that framework to include nonhuman entities and ecological systems, this article is a call for creativity and increased interdisciplinarity. And as artists who work in laboratories with scientists, alongside those whose directed love for biological systems drives a lifetime of their research projects, we are interlopers. As such, we do not try to answer scientific problems but insert fresh questions and draw speculative scenarios for an imagined future that diverges from the trajectory of modern capitalist societies' overgrowth. We do not presume to make biological systems into strict models for sociotechnical systems and abhor the eugenicist mores of misguided biopolitics, as outlined by Esposito (2012), who describes Nazism as "the realization of biology" (p. 73). Likewise, we recognize that oneto-one layering (or mirroring) of disciplinary studies can result in the compression of ideas. As Kropotkin (1902) rejected the reductionism of social Darwinism, we are wary of idealizing those systems, microbiological and ecological, that we seek to learn from. When redrawing boundaries and embedding societal systems with living systems, there are more questions than answers, questions that world systems theorists, social and ecological anthropologists, and organizational sociologists ask from their own vantages. While we engage in discourse with scholars from a wide range of fields and backgrounds, not all of those discussions are represented within this text. This article is necessarily limited in scope and scale, and we admittedly are artists who dive headfirst into vast territories. We are aware of the potential for but also the limitations of this interdisciplinary approach, and regretfully cannot thoroughly represent deep discussions across many different fields of knowledge in a single article. For this reason, instead of choosing biology, philosophy or computer science alone as a launching pad for discussion, we assume our places as artists and insert creative approaches to envision a broad and multispecies understanding of well-being. As artists, we create experiences that point to what we imagine is possible. In the context of humanity's relationship to the global community during a time of climate crisis and gross societal inequity, we point to what is needed for planetary community well-being: we imagine an ecosystemic intelligence. 


\section{Recommendations for Future Work (on Behalf of Broad Community Well-Being)}

As conceptual artists, we ask, how can we formulate future technologies that embrace all of Earth's systems? As an art collective that examines social and living systems, we take to task existing systems and anticipated intelligences that we fear are oppressive to individuals and groups, entities and ecologies, and we advocate different ways of thinking about those future intelligences. The members of Cesar \& Lois are located in different hemispheres and are influenced by different cultures, each uniquely situated within the global capitalist project. For artists as for scientists, constraints can lead to unanticipated break-throughs. When is there a better time for rethinking our current systems and for examining how those reinforce human systems' toxic relationships to nature? This is an opportune moment to step beyond our current limitations and to envision an ecosystemic AI that thinks on behalf of an ecologically expansive community. As we see it, when the world's systems are disrupted, there is an opportunity for even greater disruption that could change the course of the whole society. With ecosystems facing an onslaught of crises, ecologically-focused scholarship increasingly calls for action adverse to capitalism's aims:

On the one hand, we are confronting the question of a terminal crisis, threatening most life on the planet, civilization, and the very existence of future generations. On the other hand, attempts to solve this through technological fixes, market magic, and the idea of a 'sustainable capitalism' are mere forms of ecological denial, since they ignore the inherent destructiveness of the current system of unsustainable development-capitalism. This suggests that the only rational answer lies in an ecological revolution, which would also have to be a social revolution, aimed at the creation of a just and sustainable society. (Foster et al. 2010, p. 436)

This leads us to consider the next steps for rethinking AI. When technology serves capitalist concerns and aims, which typically involve technical advancements without ecological mandates, ${ }^{7}$ the broad ideal of community well-being that encompasses human and nonhuman entities and systems is not being served. Orienting the development of AI to this expansive community well-being promises a reorientation of human systems, with the reprioritization of the societal structures that the AI supports. This also implies the reassessment of resources and redistribution of wealth. Art projects that propose ecological or biological blockchains provoke a similar discourse around and challenges to financial systems. ${ }^{8}$ As artists provoke and probe alternative systems and reapportion the human in the planetary ecosystem through small and large interventions, new possibilities for enacting interrelationships become possible, and even plausible. It is crucial that individuals

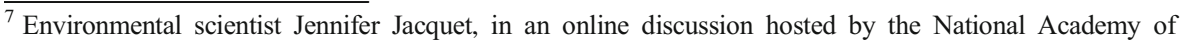
Sciences, lamented that technology and market considerations led the discussion on the possibility of octopus farms, without a consideration of ethics or implications studied in other fields and contexts (Jacquet and Prosek 2020, July 16).

${ }^{8}$ The artwork, terra0, enables a forest to manage itself through blockchain (Seidler et al. 2016).
} 
and organizations, societies and countries look to these imaginative models, and reorient and remap ourselves in order to modify what will be the future scenario for all beings.

\section{Conclusion}

Throughout this article we describe a context in which current human sociotechnical structures, based in the epistemology of modernity, serve only a selection of human societies (and select groups therein) and are not enough to respond to challenges such as societal inequities, climate crises and global pandemics. We think that an ecosystemic intelligence can expand networked thinking in alignment with a broadened view of community well-being, beyond the concerns of select humans and of human societies. This argument is rooted in theories that criticize human exceptionalism (Haraway 2008; Viveiros de Castro 2014), challenge the division between nature and humanity (Moore 2015; Tsing 2015), and link equity to social and ecological transformation (Foster et al. 2010). With these theoretical underpinnings, Cesar \& Lois created a series of artworks in which we envision new configurations of cooperation between microorganisms, humans and computer-based intelligences. The art project, Degenerative Cultures, is oriented to interactions of Physarum polycephalum with AI and databased algorithms, while [ECO]nomic Revolution draws comparisons between human societal systems and the networking microorganisms. The series of artworks provide conceptual articulations of differences between logical models for human, microbiological and computer-based decision-making and networking. Our analysis is from the perspective of the artist as an interrogator of existing systems and a dreamer of new ones, and we postulate the merging of biological and non-biological, human and nonhuman intelligences. In doing so, we conceive of the possibility of an ecosystemic $\mathrm{AI}$ - an EAI that could emerge from the crossing of human, prehuman and posthuman ways of thinking. Linking our artistic approach to this vision, we outline conceptual propositions that we consider foundational for this imagined system and correlate it with community well-being on a global scale.

The relationship between human and nonhuman intelligences is integral to the artworks of Cesar \& Lois, which layer microbio-logic with human ways of distributing resources and sharing power across individuals. The artistic intention is to critique how humanity has historically asserted power over other living beings, and, connected to this, how anthropocentrism has disconnected humanity from those beings, with dire consequences for ecosystems. In the article's discussion on Pre and PostAnthropocentric Thinking, we propound the complexity of microbiological systems, substantiated in the studies of Shaviro (2016), Jones (2015), Stiegler (1998) and Combes (2012). The intelligence of these microbiological organisms is evidenced in their biologically-based decision-making, networked connections, and distribution of resources though their networks; compiled, these traits are indicative of sentience. Within this discussion, we hypothesize that these organisms that preexisted human beings represent what we consider prehuman intelligence. In contrast with this, we consider the anthropocentric roots of AI (McCarthy et al. 1955; Minsky 1968) as well as the values inherent in the architecture of sociotechnical systems. Flusser's (1999) assertion that, in order to understand technological systems one must consider "the 
morality of things" (p. 66), has great consequence when those systems equate to machines that facilitate and shape communication networks, global economics and supply chains, which are informed by and also inform human societal values. For us, Flusser's association between apparatuses and values makes clear that, in order to conceive of an ecosystemic relationship with the living world, we must imagine new sociotechnical systems. Ecosystemic ways of thinking, which for us suggest a broader and more interconnected grounding for cross-species values, are illustrated in firstperson Indigenous accounts (Kopenawa and Albert 2013) and ecologically-oriented anthropological studies, such as in the scholarship of Kohn (2013), who seeks to better understand the complex patterns that emerge from the form of the forest (pp. 21-22).

In envisioning an ecotopian framework for artificially intelligent systems, we question, how can we effectively base AI in living networked systems, and specifically in non-neural microbiological systems where the organic decision-making is decentralized? This is an open question for all nodes in the development and evolution of AI, and it gives rise to another question: how can we move an integrated intelligence forward? Ecosystemic intelligence of many microorganisms, while lacking a neural hub, manages to support all of the nodes within a complex network. An EAI oriented to this broader sense of the network ideally serves the well-being of an Earth community, in its totality.

Acknowledgments Biologists Camila P. Cunha and Guilherme Borelli of Laboratório de Genômica e bioEnergia at Campinas State University (LGE) at UNICAMP and Scott Morgans (CSUSM) contributed to the case studies' scientific development. Biologist Betsy Read at CSUSM first introduced the artists to Physarum polycephalum, with a specimen sourced by her colleague Tom Wahlund. Jeremy Speed Schwartz contributed to the development of Degenerative Cultures. Cesar \& Lois acknowledges the research contributions of student artists of the Digital and Transdisciplinary Art Laboratory (DaTA Lab) at California State University San Marcos and those of the Laboratory for Research in Art, Science and Technology (actLAB) at UNICAMP.

Funding (information that explains whether and by whom the research was supported).

Lucy HG Solomon: Research, Scholarship, and Creative Activity (RSCA) Grant, California State University San Marcos (CSUSM).

Cesar Baio: Grant 2018/24452-1, São Paulo Research Foundation (FAPESP).

\section{Compliance with Ethical Standards}

Conflicts of Interest/Competing Interests The authors declare that they have no conflict of interest.

Availability of Data and Material (Data Transparency) not applicable.

Code Availability (Software Application or Custom Code) artistic model can be made available in response to individual requests.

Consent for Publication Though the example for this text has not been provided, we intend to offer formal and contractually binding consent for publication. 


\section{References}

Anthes, G. (2013). Inexact design: Beyond fault-tolerance. Communications of the ACM, 56(4), 18-20. https:// doi.org/10.1145/2436256.2436262.

Barrett, L., Henzi, P., \& Kendall, D. (2007). Social brains, simple minds: Does social complexity really require cognitive complexity? Philosophical Transactions of the Royal Society B: Biological Sciences, 362, 561575. https://doi.org/10.1098/rstb.2006.1995.

Ben-Jacob, E. (2008). Social behavior of bacteria: From physics to complex organization. The European Physical Journal B-Condensed Matter and Complex Systems, 65(3), 315-322. https://doi.org/10.1140/ epjb/e2008-00222-x.

Benjamin, R. (2019). Assessing risk, automating racism. Science (American Association for the Advancement of Science), 366(6464), 421-422. https://doi.org/10.1126/science.aaz3873.

Bratton, B. H. (2015). The stack. Log, 35, 128-159.

Burkart, J., Schubiger, M., \& Van Schaik, C. (2017). The evolution of general intelligence. Behavioral and Brain Sciences, 40, E195. doi:https://doi.org/10.1017/S0140525X16000959, e195.

Cassell, J. (2019). Artificial intelligence for a social world. Issues in Science and Technology, 35(4), 29-36.

Castells, M. (2000). Toward a sociology of the network society. Contemporary Sociology, 29(5), 693-699. https://doi.org/10.2307/2655234.

Chamie, J. (2020). World population: 2020 overview. Retrieved July 08, 2020, from https://yaleglobal.yale. edu/content/world-population-2020-overview.

Coeckelbergh, M. (2017). Beyond "nature". In H. Kopnina \& E. Shoreman-Ouimet (Eds.), Routledge handbook of environmental anthropology, Routledge international handbooks (pp. 105-115). London; New York: Routledge.

Combes, M. (2012). Gilbert Simondon and the philosophy of the transindividual. (T. LaMarre, Trans.). Cambridge, MA: The MIT Press.

Crawford, K., \& Joler, V. (2018). Data visualization and artwork. In Anatomy of an AI system: The Amazon Echo as an anatomical map of human labor, data and planetary resources. AI Now Institute and Share Lab https://anatomyof.ai. Accessed 20 September 2020.

Crutzen, P. (2002). Geology of mankind. Nature, 415(23), 23. https://doi.org/10.1038/415023a.

Esposito, R. (2012). Terms of the political: Community, immunity, biopolitics (1st ed., commonalities). New York: Fordham University press.

Flikkema P. G., \& Leid J. G. (2005). Bacterial communities: A microbiological model for swarm intelligence. Proc - 2005 IEEE Swarm Intell Symp SI, 427-430. https://doi.org/10.1109/SIS.2005.1501655.

Flusser, V. (1999). The shape of things: a philosophy of design. (a. Mathews, trans.). (1st English ed.). London: Reaktion.

Foster, J., Clark, B., \& York, R. (2010). The ecological rift: Capitalism's war on the earth. New York: Monthly Review Press.

Fricker, M., Boddy, L, \& Bebber, D. (2007). Network organisation of mycelial fungi. Biology of the Fungal Cell, R. J. Howard \& N. A. R. Gow, springer Ed., 309-330.

Fricker, M. D., Heaton, L. L. M., Jones, N. S., \& Boddy, L. (2017). The mycelium as a network. Microbiology Spectrum, 5(3). https://doi.org/10.1128/microbiolspec.FUNK-0033-2017.

Gibson, B., Wilson, D. J., Feil, E., \& Eyre-Walker, A. (2018). The distribution of bacterial doubling times in the wild. Proceedings. Biological Sciences, 285(1880). https://doi.org/10.1098/rspb.2018.0789.

Gómez-Barris, M. (2017). The extractive zone: Social ecologies and decolonial perspectives. Durham: Duke University Press. https://doi.org/10.2307/j.ctv1220n3w.

Gordon, D., Ilieș, G., \& Traniello, J. (2017). Behavior, brain, and morphology in a complex insect society: Trait integration and social evolution in the exceptionally polymorphic ant pheidole rhea. Behavioral Ecology and Sociobiology, 71(11), 1-13. https://doi.org/10.1007/s00265-017-2396-z.

Hannah, L. (2012). Saving a million species: Extinction risk from climate change. Washington, DC: Island Press/Center for Resource Economics. https://doi.org/10.5822/978-1-61091-182-5.

Haraway, D. (2008). When species meet (Posthumanities; 3). Minneapolis: University of Minnesota Press.

Haraway, D. (2016). Staying with the trouble: Making kin in the Chthulucene (experimental futures). Durham: Duke University Press.

Harden, C. P., Chin, A., English, M. R., Fu, R., Galvin, K., Gerlak, A. K., Mcdowell, P. F., McNamara, D. E., Peterson, J. M., LeRoy Poff, N., Rosa, E. A., Solecki, W. D., \& Wohl, E. E. (2014). Understanding human-landscape interactions in the "Anthropocene". Environmental Management, 53(1), 4-13. https:// doi.org/10.1007/s00267-013-0082-0. 
Harwood, G. (2019). Teaching critical technical practice. In L. Bogers \& L. Chiappini (Eds.), The Critical Makers Reader: (Un) learning Technology (pp. 29-37). Institute of Network Cultures.

Herzing, D. L. (2014). Profiling nonhuman intelligence: An exercise in developing unbiased tools for describing other 'types' of intelligence on earth. Acta Astronautica, 94, 676-680.https://doi.org/10. 1016/j.actaastro.2013.08.007.

Howell, S. (1996). Nature in culture or culture in nature? Chewong ideas of 'humans' and other species. In G. P. Descola \& P. Descola (Eds.), Nature and Society: Anthropological Perspectives (pp. 127-144). Routledge.

IPBES. (2019). Global assessment report on biodiversity and ecosystem services of the Intergovernmental Science-Policy Platform on Biodiversity and Ecosystem Services. In E. S. Brondizio, J. Settele, S. Díaz, \& H. T. Ngo (Eds.). Bonn: IPBES secretariat Retrieved from https://ipbes.net/global-assessment.

Jacquet, J., \& Prosek, J. (2020, July 16). Jennifer Jacquet and James Prosek in conversation. D.C. Art Science Evening Rendezvous (DASER), National Academy of Sciences. Retrieved from http://www.cpnas.org/ events/daser-071620.html

Johnson, B., \& Jasper, R. (2016). Complex patterns of differential expression in candidate master regulatory genes for social behavior in honey bees. Behavioral Ecology and Sociobiology, 70(7), 1033-1043. https:// doi.org/10.1007/s00265-016-2071-9.

Johnson, S. (2003). Emergência: a vida integrada de formigas, cérebros, cidades e softwares. Rio de Janeiro: Jorge Zahar Ed.

Jones, J. (2015). Exploiting environmental computation in a multi-agent model of slime mould. AIP Conference Proceedings, 1648. doi:https://doi.org/10.1063/1.4912814.

Kimmerer, R. W. (2013). Braiding sweetgrass: Indigenous wisdom, scientific knowledge, and the teachings of plants (First ed.). Minneapolis: Milkweed Editions.

Kohn, E. (2007). How dogs dream: Amazonian natures and the politics of transspecies engagement. American Ethnologist, 34(1), 3-24. https://doi.org/10.1525/ae.2007.34.1.3.

Kohn, E. (2013). How forests think: Toward an anthropology beyond the human. Berkeley: University of California Press.

Kopenawa, D., \& Albert, B. (2013). The falling sky: Words of a Yanomami shaman. (N. Elliot \& A. Dundy, Trans. Cambridge: The Belknap Press of Harvard University Press.

Kopenawa, D., \& Albert, B. (2015). A queda do céu. Palavras de um xamã Yanomami [The Falling Sky: Words of a Yanomami Shaman]. (B. Perrone-Moisés, Trans.). (E. Viveiros de Castro, Intro.). São Paulo: Companhia das Letras.

Kropotkin, P. (1902). Mutual aid: A factor of evolution. New York: McClure Phillips \& Co..

LaFrance, A. (2016). Technology, the faux equalizer. The Atlantic. Retrieved from https://www.theatlantic. com/technology/archive/2016/03/half-full-tech/476025/

MacLeod, C., \& Capanni, N. (2010). Artificial biochemical networks: A different connectionist paradigm. Artificial Intelligence Review, 33(1-2), 123-134. https://doi.org/10.1007/s10462-009-9149-y.

Mamo, L., \& Fishman, J. (2013). Why justice? Introduction to the special issue on entanglements of science, ethics, and justice, Science, Technology \& Human Values, 38, 159-175.

Mayne, R., \& Adamatzky, A. (2015). Slime mould foraging behaviour as optically coupled logical operations. International Journal of General Systems, 44(3), 305-313. https://doi.org/10.1080/03081079.2014. 997528.

McCarthy, J., Minsky, M., Rochester, N., \& Shannon, C. (1955). A proposal for the Dartmouth summer research project on artificial intelligence. AI Magazine, 27(4), 12-14. https://doi.org/10.1609/aimag. v27i4.1904.

Miller, K. W. (2011). Moral responsibility for computing artifacts: 'The Rules.'. IT Professional, 13(3), 5759. https://doi.org/10.1109/mitp.2011.46.

Minsky, M. (Ed.). (1968). Semantic information processing. Cambridge: The MIT Press.

Morse, S. F., Dick, C. W., Patterson, B. D., \& Dittmar, K. (2012). Some like it hot: Evolution and ecology of novel endosymbionts in bat flies of cave-roosting bats (Hippoboscoidea, Nycterophiliinae). Applied and Environmental Microbiology, 78(24), 8639-8649. https://doi.org/10.1128/aem.02455-12.

Moore, J. (2015). Capitalism in the web of life: Ecology and the accumulation of capital (1st ed.). New York: Verso.

Nakagaki, T. (2001). Smart behavior of true slime mold in a labyrinth. Research in Microbiology, 152(9), 767-770. https://doi.org/10.1016/s0923-2508(01)01259-1.

National Research Council (2014). Can Earth's and society's systems meet the needs of 10 billion people? Summary of a Workshop. The National Academies Press. https://doi.org/10.17226/18817. 
Nolan, J. M., \& Schultz, W. (2015). Prosocial behavior and environmental action. In D. A. Schroeder \& W. G. Graziano (Eds.), The Oxford Handbook of Prosocial Behavior (pp. 626-652). Oxford; NewYork: Oxford University Press.

Pinker, S. (2010). The cognitive niche: Coevolution of intelligence, sociality, and language. Proceedings of the National Academy of Sciences USA, 107(2), 8993-8999. https://doi.org/10.1073/pnas.0914630107.

Ratto, M., \& Hertz, G. (2019). Critical making and interdisciplinary learning: Making as a bridge between art, science, engineering, and social interventions. In L. Bogers \& L. Chiappini (Eds.), The Critical Makers Reader: (Un) learning Technology (pp. 17-28). Institute of Network Cultures.

Ribeiro, E. M. S., Arroyo-Rodríguez, V., Santos, B. A., Tabarelli, M., \& Leal, I. R. (2015). Chronic anthropogenic disturbance drives the biological impoverishment of the Brazilian Caatinga vegetation. Journal of Applied Ecology, 52(3), 611-620. https://doi.org/10.1111/1365-2664.12420.

Seidler, P., Kolling, P., \& Hampshire, M. (2016). terra0: Can an augmented forest own and utilise itself? [white paper]. Berlin University of the Arts. Retrieved from https://terra0.org/assets/pdf/terra0_white_ paper_2016.pdf

Shaviro, S. (2010). Fruit flies and slime molds. Retrieved from http://www.shaviro.com/Blog/?p=955

Shaviro, S. (2016). Discognition. London: Repeater.

Sinders, C. (2019). Making critical ethical software. In L. Bogers \& L. Chiappini (Eds.), The Critical Makers Reader: (Un) learning Technology (pp. 86-94). Institute of Network Cultures.

Smith, M. (2011). Against ecological sovereignty: Ethics, biopolitics, and saving the natural world (Posthumanities; 16). Minneapolis: University of Minnesota Press.

Stiegler, B. (1998). Technics and time 1: The fault of Epimetheus. (R. Beardsworth \& G. Collins, Trans.). Stanford: Stanford University Press.

Strang, V. (2017). Justice for all. In Kopnina, H. \& E. Shoreman-Ouimet (Eds.), Routledge handbook of environmental anthropology (1st ed.) (Routledge international handbooks) (pp. 259-275). London; New York: Routledge. https://doi.org/10.4324/9781315768946-21.

Taddeo, M., \& Floridi, L. (2018). How AI can be a force for good: An ethical framework will help to harness the potential of AI while keeping humans in control. Science, 361(6404), 751-752. https://doi.org/10. 1126/science.aat5991.

Tollefson, J. (2017). Trump pulls United States out of Paris climate agreement. Nature, 546(7657), 198. https://doi.org/10.1038/nature.2017.22096.

Tomasello, M. (2014). A natural history of human thinking. Cambridge: Harvard University Press.

Tsing, A. L. (2015). The mushroom at the end of the world: On the possibility of life in capitalist ruins. Princeton: Princeton University Press. https://doi.org/10.2307/j.ctvc77bcc.

Viveiros de Castro, E. (2014). Cannibal metaphysics. In. P. Skafish (Ed.), Minneapolis. Minnesota: University of Minnesota Press..

Publisher's Note Springer Nature remains neutral with regard to jurisdictional claims in published maps and institutional affiliations.

\section{Affiliations}

\section{Lucy HG Solomon ${ }^{1} \cdot$ Cesar Baio $^{2}$}

Cesar Baio

cesarandloiscollective@gmail.com

1 Department of Art, Media, and Design, California State University San Marcos, 333 S. Twin Oaks Valley Road, San Marcos, CA 92096, USA

2 Department of Multimedia, Media and Communication, Universidade Estadual de Campinas, Cidade Universitária Zeferino Vaz - Barão Geraldo, Campinas, SP 13083-970, Brazil 